\title{
Performance, regulated and unregulated exhaust emission of a stationary compression ignition engine fueled by water-ULSD emulsion
}

\author{
${ }^{1}$ Hayder A Dhahad, ${ }^{2}$ Miqdam T Chaichan, ${ }^{3}$ T. Megaritis \\ ${ }^{1}$ Directorate of laboratories and training, University of Technology, Baghdad, Iraq \\ ${ }^{2}$ Energy and Renewable Energies Technology Center, University of Technology, Baghdad, Iraq \\ Centre for Advanced Powertrain and Fuels Research School of Engineering and Design, Brunel University, \\ London, UK
}

\begin{abstract}
The interest in water-diesel emulsion fuel (W/D) is increased to rise recently because of the significant reduction in emissions from diesel exhaust, especially NOx and PM. Perhaps, the most important reason to reduce its spread commercially can be referred to the use of surfactant in such fuels to lengthen its stability and prevents the separation of components. The use of surfactant additives increases the cost of fuel and reduces its acceptance in popular. In this study, a diesel engine configured for experimental investigations was fueled by ultra-low sulfur diesel (ULSD) and a diesel-water emulsion (EM) at a speed of $1500 \mathrm{rpm}$ and using a load of 2.5 and 5 bars was used. Combustion properties and contaminants such as smoke number, $\mathrm{HC}, \mathrm{CO}$, and NOx were studied. As for the first time (in the case of an engine running with a water-diesel emulsion) irregular pollutants for W/D emulsion were measured.

The measured results indicated that the use of water-diesel emulsion reduced the heat released in the combustion chamber, which causes an increase in the brake specific fuel consumption and ignition delay. For the tested loads, the diffusion combustion duration for EM was decreased when the injection timing was retarded while the opposite was occurred for premixed combustion duration. The regulated NOx and Smoke number were reduced when EM was used compared to ULSD while CO and HC levels were increased depending on injection timing (they were higher at restarted timing). The unregulated emissions measured (Formaldehyde, Acetaldehyde, Methane, Acetylene, Ethylene, and propylene, Ammonia, and Acetone) were increased with using EM, especially at no and low loads, indicating the high impact of temperature on these pollutants formation.

Key words: Ultra low sulfur diesel, water diesel emulsion, regulated and unregulated pollutants, combustion characteristics
\end{abstract}

$\begin{array}{ll}\text { Nomenclature } & \text { End of combustion } \\ \text { EOC } & \text { End of premixed burn } \\ \text { EOPMB } & \text { The losses by the crevices. } \\ H_{i} d m_{i} & \text { Ignition delay } \\ \text { ID } & \text { The resolution of the heat release rate expressed in 1/measured points in 0.125 CAD. } \\ \mathrm{k} & \text { Fuel mass flow rate. } \\ m_{f}^{\circ} & \text { Engine output power. } \\ P & \text { The in-cylinder pressure. } \\ p & \text { Premixed burn fraction } \\ \text { PMBF } & \text { Convective heat transfer to the cylinder walls. } \\ Q_{h t} & \text { Start of combustion } \\ \text { SOC } & \text { Start of injection } \\ \text { SOI } & \text { Internal energy. } \\ U_{s} & \text { The cylinder volume. } \\ V & \text { Work output. } \\ W & \text { Adiabatic index (specific heats ratio). } \\ \gamma & \text { Crank angle degree. }\end{array}$

Introduction

The high demand for fossil fuels increased because of the expansion in population and in the requirements of human comfort and energy supply concurrent with shrinkage of oil sources and high volatility in its prices, and if 
the environmental pollution problems resulting from emissions of burning fossil fuels are all strongly drive to increase the investigation of replacing fossil fuels with clean, available, environmentally friendly, low-cost fuel [1-3]. The extensive use of diesel engines in land, sea, air, agricultural and industrial equipment and heavy construction equipment has made it a target for researchers to reduce its pollution emissions as well as to improve its thermal efficiency. The use of alternative fuels for diesel fuel is not new, but began since Rudolf Diesel built the first engine [4]. The researchers tested with many alternatives such as biodiesel [5-7], adding natural gas to diesel [8], adding hydrogen gas to diesel [8] and using a diesel-water emulsion [9].

The water-diesel (W/D) emulsion has begun to attract considerable attention as an alternative fuel because of the many results indicated by the researchers that reflect improvements in engine performance and reduced concentration of pollutants emitted from it [10]. A preparation of water-diesel emulsion is done by mixing suitable amounts of water and diesel with proper surfactant for continuous mixing of materials and emulsion stability for as long as possible [11]. The most important obstacle to the spread of this alternative is the need for surfactant in its production, which increases the cost and restricts commercialization [12]. If the emulsifier components fail due to surface tension deposition during engine operation, the engine is highly exposed to fail, which may damage internal engine parts. The specialists divided the surfactants into four types according to their stability: the product emulsifier: stable, high, unstable, and water. Typically, stable stabilizing emulsions can be extended to a few months depending on factors such as application temperature, type and ratio of surface agent, viscosity, gravity and water content [13, 14]. The source [15] noted that any emulsion (W/D) emitted in the phases of serial formation is flocculation, attracting, the last stages of sedimentation or fat. In the phase of flocculation, the droplets are attracted internally to each other. In the attracting phase, the attracted droplets start to form larger droplets. In the sedimentation phase, the result of the different densities of the previous two phases is observed. There are many surfactants used by researchers and experts are Span 80 (Sorbitanmonooleate); Span 80 and Tween 80 (Polyoxyethylenenonylphenyl ether); Triton X-100 (or); and Dai- Seiyaku (Solgen and Noigen TDS-30) [16, 17].

Water-diesel emulsion has an important feature, which is small explosion or blowing. When the emulsion droplets temperature rises to a temperature higher than the water boiling point, the small water droplets inside the emulsion drop begin to evaporate rapidly causing what can be called "little oscillation" or "blowing". The small explosion is the dissolution of a full emulsion droplet, but blowing is a relatively micro-explosion gets on the surface of droplets, and even if it happens, part of the basic fuel is separated from the surface of droplets, and this entire process called "dissolution" [18]. The contact between diesel and air is increased by dissipating the emulsifier and improving the combustion efficiency, thereby reducing the PM emission rate. The latent heat of evaporated water also reduces the combustion temperature, effectively reducing nitrogen oxides emitted [19]. The low melting temperatures of the emulsifier cause a decrease in the total heating rate and its thermal efficiency, so it is one of the weak points of this fuel. The use of water-diesel emulsions should also be used as a semi-sulfur-free diesel to prevent corrosion of metal parts [20].

The researchers used three methods to produce water-diesel mixtures [21], namely, injecting water into the combustion chamber intake inlet, direct injection into the cylinder, and using a water-diesel emulsion [22]. Several previous studies [23-25] have agreed that diesel-water mixtures reduce the emission of soot and nitrogen oxides together. This reduction is due to three main reasons: the water has a high latent evaporation temperature and causes a decrease in the maximum burning temperature, which reduces the soot and nitrogen oxides emitted [26]. The interaction of water and gas accelerates the oxidation of soot [27]. Finally, the small explosion of water leads to the breakage of fuel droplets into small parts, which improves mixing the fuel with the air, as a result it limits the generation of soot [28].

Several previous studies have shown inconsistent results when using a water-diesel emulsion for brake specific fuel consumption (BSFC), brake thermal efficiency (BTE), carbon monoxide (CO), and hydrocarbons (HC) emissions. The researchers $[29,30]$ showed that BSFC decreased by increasing the concentration of water in diesel within the emulsifier, while researchers [31, 32] found that BSFC increased significantly by increasing water concentrations in the emulsion. References [33,34] reported that $\mathrm{CO} 2$ emissions increased with the use of water-diesel emulsion compared to diesel due to low combustion temperatures and the elevation of $\mathrm{OH}$ radicals [35], while references [36, 37] explained that $\mathrm{CO}$ and $\mathrm{HC}$ missions were slightly reduced when water emulsion was used normally due to the small blasting which improved the fuel combustion process.

Iwai et al. [38] compared experimentally between performance and emissions of neat diesel with water injection at the intake manifold, and when the engine was run by a water-diesel emulsion of $15 \%$ and $30 \%$ water addition. The results of the study showed a significant reduction in nitrogen oxides and soot emissions when using wateremulsion. Fuel consumption was also reduced. Ref. [39] added 1-4 dioxane to an emulsion of $89.8 \%$ diesel + $10 \%$ water $+0.2 \%$ surfactant with different concentrations $(5,10,15$ and $20 \%)$ to study the performance and contaminants of a single-cylinder diesel engine. The results of the study showed that the BTE for the emulsifying mixture $+10 \%$ 1- 4 dioxane increased by $7 \%$ compared to diesel while the BSFC decreased by $7.5 \%$. The concentrations of smoke emissions, hydrocarbons (HC), and carbon monoxide (CO) were decreased by $27.83 \%$, $31.66 \%$, and $15 \%$, respectively, compared to diesel. Ref. [40] studied the influence of the addition of water to the 
water-diesel emulsion by three different weight ratios $(40 \%, 20 \%$ and $30 \%)$. The experiments were carried out in a fixed-size combustion chamber using a high-speed insulation system to track the processes resulting from fuel spraying and combustion. The researchers concluded that the amount of water added to the emulsifier significantly affected the spray and combustion properties of the emulsifier as well as increasing the ignition delay. The results of the study showed that the emission of soot is significantly reduced when using emulsifier.

Experimental studies have concluded that water content in the emulsifier and engine load have a key role in engine performance. However, the laboratory results showed inconsistent results for these two parameters. For example, Ref. [41] indicated that the use of an emulsion with a water content of less than $20 \%$ causes high BTE. In contrast, Ref. [42] study showed that the highest value of the BTE was when water was added by 5\%. Ref. [43] contrasted the results when he explained that the best BTE can be reached using a water-diesel emulsion by adding water by $10 \%$ at all engine loads. Ref. [44] investigated practically the impact of engine load change on performance when burning water-diesel emulsions. The addition of $20 \%$ water in the emulsifier resulted in maximum cylinder pressure and an increase in pressure compared to other addition ratios, the researchers claimed. Emulsifier fuel also resulted in lower NOx and PM emissions while the CO and CO2 levels were increase in high and low loads compared to neat diesel.

Cok and Abdullah [45] found that the addition of water to diesel by $15 \%$ would increase the BSFC by $7.2 \%$ at $2800 \mathrm{rpm}$. However, at the same time it reduced the nitrogen oxides emissions. Thus, the reduction of NOx emissions can offset the damage of increasing fuel consumption and overcome this defect through mineral additives in fuel as an effective and efficient strategy. Scientists have increased interest in mineral additives added to fuel after the great revolution of nanotechnology. Many researchers have added small amounts of these nanoparticles to the water-diesel emulsion and studied the effect of this addition on combustion properties and pollutants.

Ref. [46] used water-diesel emulsion to improve fuel properties and study the performance of the engine and the pollutants emitted from it. The researchers added a number of nanomaterials $(50 \mathrm{ppm})$ such as aluminum oxide (Al2O3), copper oxide $(\mathrm{CuO})$, magnesium oxide $(\mathrm{MgO})$, manganese oxide $(\mathrm{MnO})$ and zinc oxide to emulsion consisted of $10 \%$ water $+90 \%$ diesel. The addition of nanoparticles to the emulsion increased the density, viscosity, water drop and kinetic volume, thermal oxidation, and caused a decrease in the stability period, which resulted in a reduction of $\mathrm{CO}$ emissions by up to $17 \%$. Among the nano-materials tested, $\mathrm{Al} 2 \mathrm{O} 3$ was the best nano-additive added, as it reduced BSFC, NOx and CO compared to other types of Nanoparticles tested.

Ref. [47] added cerium oxide components $(90 \mathrm{ppm})$ to an emulsion of water-diesel-biodiesel at mixed water concentrations of $(2 \%, 4 \%$, and $6 \%$ by weight). The results of the tests showed that mixing air with fuel improved when adding water to biodiesel because of the micro-explosions. However, when water is added by $6 \%$ concentration, the combustion was degraded because the micro-explosion affect was influenced by the increased viscosity. The study also showed low emissions of CO2, PM, NOx and HC. Mineral additives in mixed fuel have improved BTE, BSFC and reduced emissions by improving combustion characteristics as it behaved as catalytic activity during the combustion process.

Ref. [48] studied adding nano- $\mathrm{Al} 2 \mathrm{O} 3$ to water-diesel emulsion fuel. The nano-Al2O3 with diameter of $51 \mathrm{~nm}$ was added with variable weight ratios to water $(1 \%, 3 \%, 5 \%, 7 \%$ and $10 \%)$. The resulting suspension was added at $10 \%$ volume to diesel and completely mixed. Nano-alumina addition to diesel-water suspension caused a $5.5 \%$ increase in BTE and fuel consumption fell by $3.94 \%$ compared to diesel fuel. This addition also caused a decrease in concentrations of NOx, PM, CO, HC, and engine noise compared to diesel.

Diesel engine exhaust gases contain a variety of contaminants harmful to health and the environment. Some of these missions have legislated and laws with strict limits such as CO, HC, NOx, and PM, and there are many other types that have not been regulated by standards despite their high risk to public health. These unregulated pollutants emitted by diesel engine exhaust such as alkanes, aldehydes, benzene, toluene, selenium (BTX), alcohol and ketones [49]

Most studies have focused on the verification of regulated pollutants emissions, but unregulated emissions have not found their share of this concentration. Examination of concentrations of exhaust pollutants such as formaldehyde, acetaldehyde, 1.3-potadine, benzene, toluene and selenium (BTX) is found in very limited numbers of available literature. Interest in these contaminants has increased since many studies have reported a significant negative impact on health. Unfortunately, we did not find any studies dealing with the concentrations of irregular pollutants for diesel-water emulsion, and in contrast there are some studies that dealt with these pollutants for diesel-biodiesel fuels [50-57]. Therefore, this study aims to verify the combustion specification with emphasis on the study of the regulated and unregulated emissions of ultra-low sulfur diesel (ULSD) mixed with water and surfactant.

Experimental Setup

Materials 
Two kinds of fuels were used in this study. The ultra-low sulfur diesel fuel (ULSD) was ordinary lab diesel fuel. The second was water diesel emulsion with $15 \%$ water content. The properties of both fuels are summarized in Table 1.

Table 1 used fuels properties

\begin{tabular}{|c|c|c|c|}
\hline Parameter & Units & Diesel (ULSD) & Water-diesel emulsion \\
\hline "Chemical formula & & $\mathrm{C} 14 \mathrm{H} 26.18$ & 51 \\
\hline "Cetane number" & - & 54 & 835 \\
\hline "Density at $15^{\circ} \mathrm{C} "$ & $\mathrm{~kg} / \mathrm{m}^{3}$ & 827.1 & $2-7$ \\
\hline "Viscosity at $40^{\circ} \mathrm{C} "$ & $\mathrm{cSt}$ & 2.45 & 41.4 \\
\hline "LCV" & $\mathrm{MJ} / \mathrm{kg}$ & 43.29 & $<31$ \\
\hline "Sulphur" & $\mathrm{mg} / \mathrm{kg}$ & 10 & 19.5 \\
\hline "Total aromatics" & $\mathrm{wt} \%$ & 23.9 & $<0.01$ \\
\hline "Ash content" & $\mathrm{wt} \%$ & $<0.005$ & 72.63 \\
\hline "Carbon" & $\mathrm{wt} \%$ & 86.44 & 14.9 \\
\hline "Hydrogen" & $\mathrm{wt} \%$ & 13.56 & 0.05 \\
\hline "Oxygen" & $\mathrm{wt} \%$ & 00 & - \\
\hline "Cloud point" & ${ }^{\circ} \mathrm{C}$ & -10 & 58 \\
\hline "Flash point" & ${ }^{\circ} \mathrm{C}$ & 68 & \\
\hline
\end{tabular}

\section{Engine testing setup}

A diesel engine produced by Ford Motor Co., within the Duratorq series, was used in this study, known as the Puma engine. This high-speed direct injection engine has been installed to become a stationary motor within a test cell and was connected to a Schenk eddy-current dynamometer. Fig. 1 represents a schematic diagram of the experimental engine setup while Fig. 2 shows a photograph of the engine. Table 2 lists the engine specifications The engine is powered by a turbocharger to balance the intake of the engine at low or high speeds. Engine control is done via the ECU connected to a computer (GREDI v 2.298) to write and modify engine maps. Use GREDI to deal directly with ECU parameters. The unit is equipped with maps when the engine is not operational and can be modified over the Internet. GREDI is used to adjust engine standards such as: injection strategy, injection pressure and timing, EGR levels, and boost pressure.

Fig. 1, schematic test rig used in

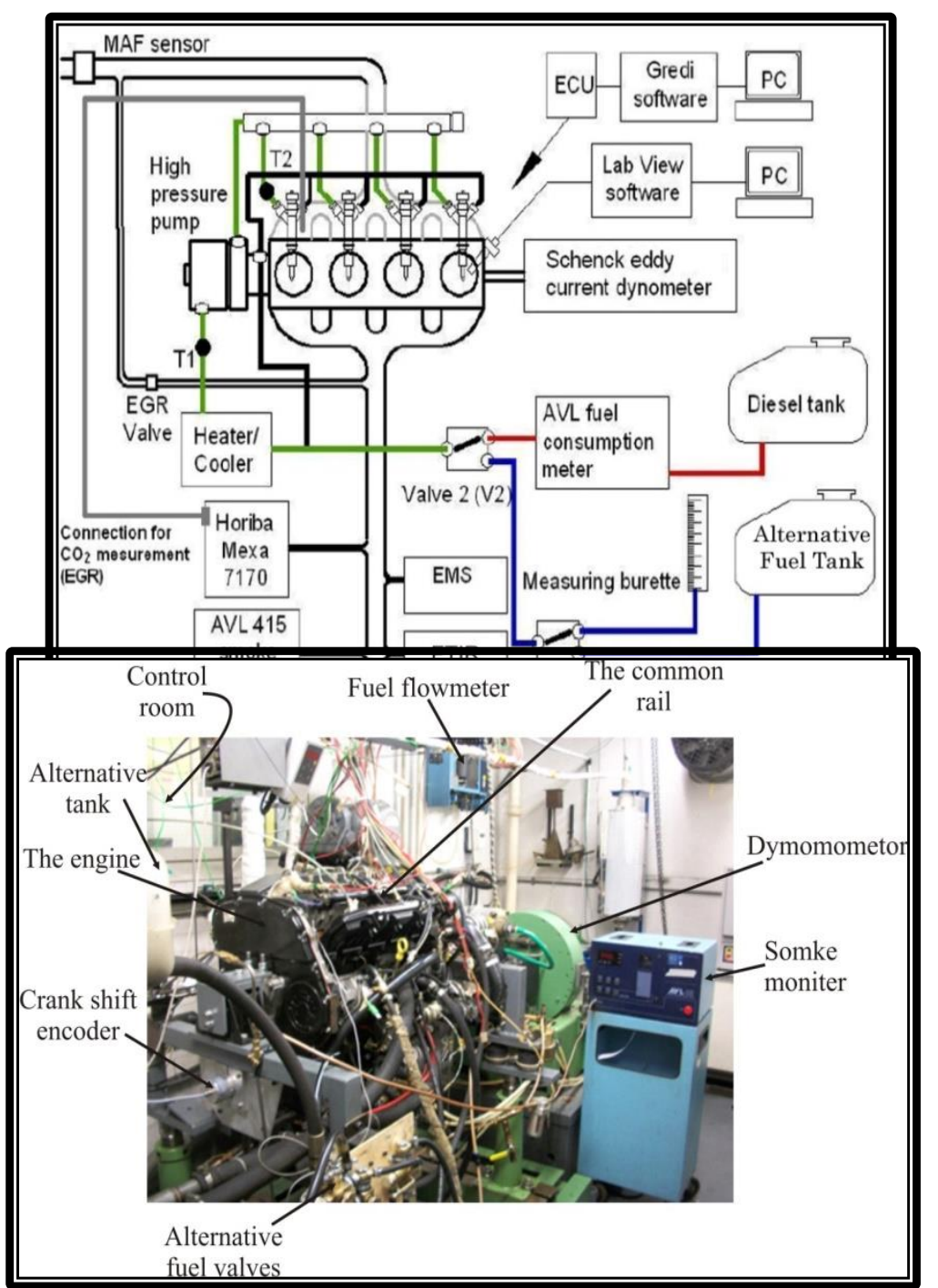

diagram of the the experiments 
Fig. 2 photograph of the engine

To take samples of the engine exhaust gas, a branch from the exhaust manifold was installed in the form of a descending tube. The pipeline was equipped with a number of outlets and connected to the pollutant measuring devices. The sampling ports are made of stainless steel to confirm the collection of samples of the exhaust gas is achieved from the exhaust pipe central part at a 90 degree angle to the exhaust gas flow. Taking this action was to minimize any errors that may result from the impact of gas friction flowing into the wall.

Table 2, Engine specifications

\begin{tabular}{|c|c|c|c|}
\hline & "Number of Cylinders" & 4 & \multirow{13}{*}{$\begin{array}{l}\text { sampling } \\
\text { analyzer Horiba } \\
\text { 7170DEGR used } \\
\text { regulated exhaust } \\
\text { as } \mathrm{CO}, \mathrm{CO} 2 \text {. THC }\end{array}$} \\
\hline & "Cylinder Bore" & $86 \mathrm{~mm}$ & \\
\hline & "Crankshaft stroke" & $86 \mathrm{~mm}$ & \\
\hline & "Swept Volume" & $1998.23 \mathrm{cc}$ & \\
\hline & "Compression Ratio" & $18.2: 1$ & \\
\hline & "Maximum Cylinder Pressure" & $150 \mathrm{bar}$ & \\
\hline & "Piston Design" & Central bowl in piston & \\
\hline & "Nominal Bowl Volume" & $21.7 \mathrm{cc}$ & \\
\hline & "Oil Type" & $15 \mathrm{~W} 40$ & \\
\hline & "Water Temperature" & $70^{\circ} \mathrm{C}$ & \\
\hline \multirow{3}{*}{$\begin{array}{l}\text { Exhaust gas } \\
\text { The gas } \\
\text { MEXA- } \\
\text { to measure }\end{array}$} & "Maximum Turbine Speed" & $180000 \mathrm{rpm}$ & \\
\hline & "Idle Engine Speed" & $750 \pm 5 \mathrm{rpm}$ & \\
\hline & "Maximum No Load Speed" & $4800 \pm 50 \mathrm{rpm}$ & \\
\hline $\begin{array}{l}\text { concentration data } \\
\text { experimental matrix. } \\
\text { performed, a daily ca }\end{array}$ & $\begin{array}{l}\text { alyzer is based on several me } \\
\text { thod was used to measure } \\
\text { ethod. Flame ionization detect } \\
\text { s recorded at } 180 \text {-second inter } \\
\text { All trials in this study were rep } \\
\text { bration of Horiba was done. H }\end{array}$ & $\begin{array}{l}\text { alyzing each gas. For } \\
\mathrm{CO} \text { emissions. Emit } \\
\text { i to measure unburnt } 1 \\
\text { e measurement is give } \\
\text { imes to ensure repeata } \\
\text { alyzer is shown in Fig. }\end{array}$ & $\begin{array}{l}\text { aple, non-dispersive } \\
\text { NOx measured by } \\
\text { carbons (THC). HC } \\
\text { ice per point in the } \\
\text { Before testing was }\end{array}$ \\
\hline $\begin{array}{l}\text { Smoke number was } \\
\text { paper used by a pho } \\
\text { automatically chang } \\
\text { concentration of the } \\
0 \text { is the white paper }\end{array}$ & $\begin{array}{l}\text { easured using An AVL } 415 \mathrm{~S} \text { sm } \\
\text { electric head. A fixed sample si } \\
\text { the size of the samples taken, } \\
\text { moke is measured as accurately a } \\
\text { lter while } 10 \text { is completely black } \\
\text { nncentration of the soot of } 32000 \\
\text { d determined by the instrument. }\end{array}$ & $\begin{array}{l}\text { r; this device measures th } \\
\text { exhaust gas passes throl } \\
\text { changing the effective } 1 \\
\text {. The smoke meter gives } \\
\text { re, the number } 0 \text { represe } \\
\text { he average of three sam! }\end{array}$ & $\begin{array}{l}\text { lackness of the filter } \\
\text { the filter. The scale } \\
\text { th to ensure that the } \\
\text { dients from } 0 \text { to } 10 \text {, } \\
\text { a concentration of } 0 \\
\text { measurements were }\end{array}$ \\
\hline
\end{tabular}




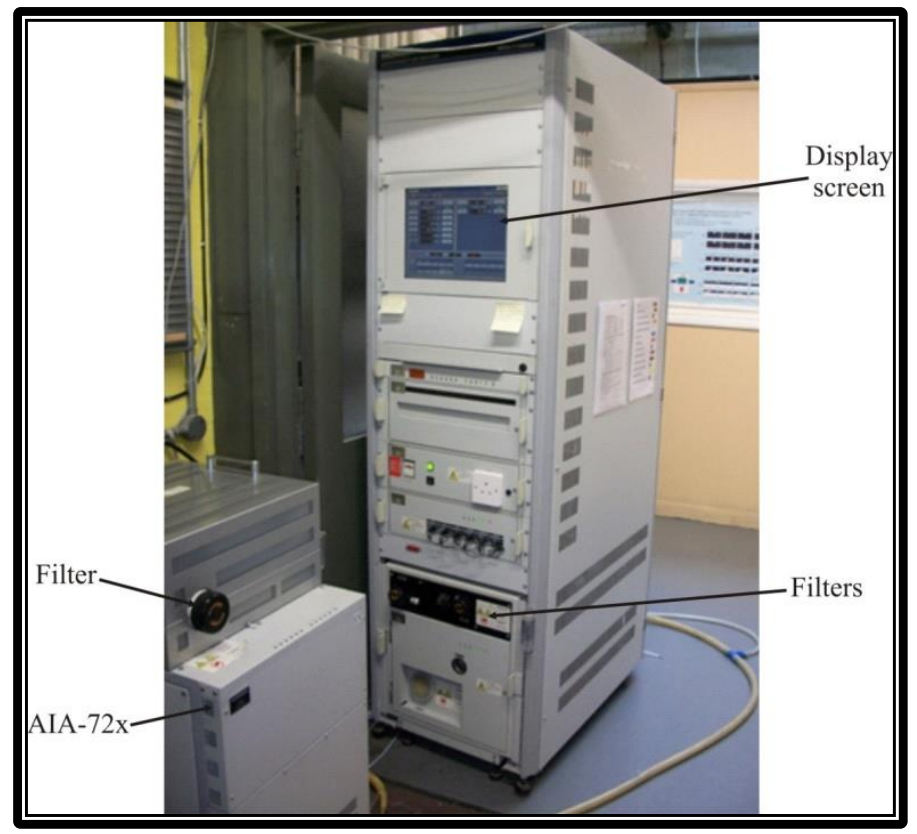

Fig. 3 A photograph of Horiba Gas Analyzer

\section{Unregulated gases measurements}

Fourier Transform Infrared (FTIR) Spectrometry type (a Multigas 2030) was used to measure unregulated emissions gases. This measurement technique is very fast and sensitive. Active infrared species are not measured, for example they do not measure concentrations of oxygen, hydrogen and nitrogen. Fig. 4 shows the results from a sample of 10 typical components at a concentration of $50 \mathrm{ppm}$. This meter was connected to the FLS01 sampling device. FTIR is cooled using liquid nitrogen from BOC Specialty Gases Ltd.

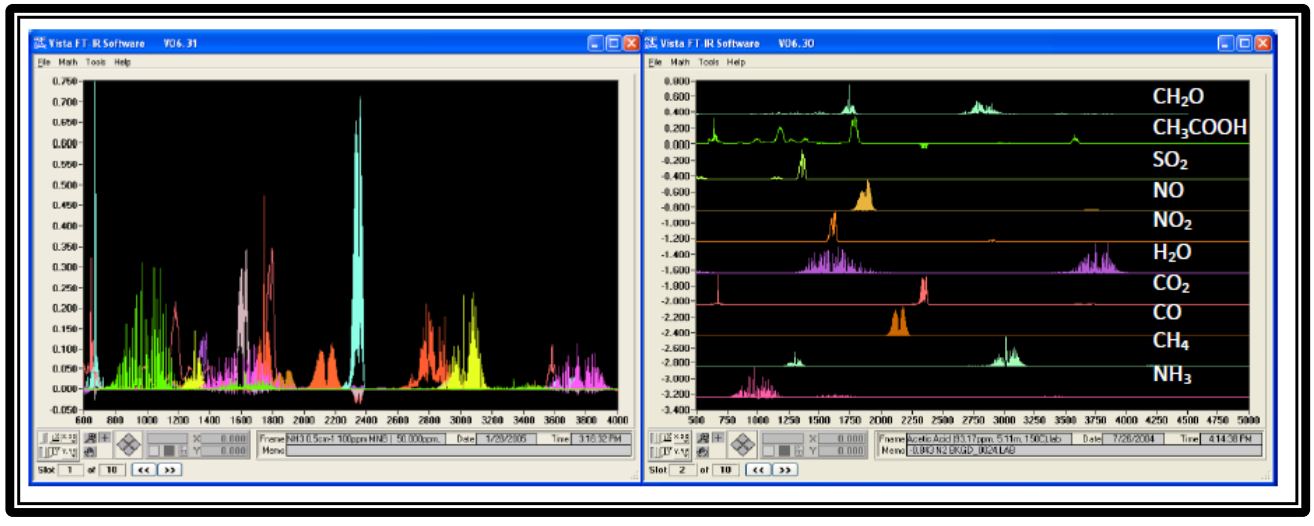

Fig. 4 Overlay and stacked spectra for 10 typical components at 50 ppm concentration

Fig. 5 shows a photo of Multigas 2030 FTIR image. MKS company has developed a predefined list of reference spectra (known as "recipe") designed to measure typical diesel emission components and includes 20 components. This recipe was used throughout the study without change. Table 3 shows the ingredients of the recipe mentioned. The FTIR instrument cell and the sampling unit are disinfected using dry Nitrogen with 2 bar pressure and $0.5 \mathrm{~L} / \mathrm{min}$ flow rate for at least 10 minutes before each test. 


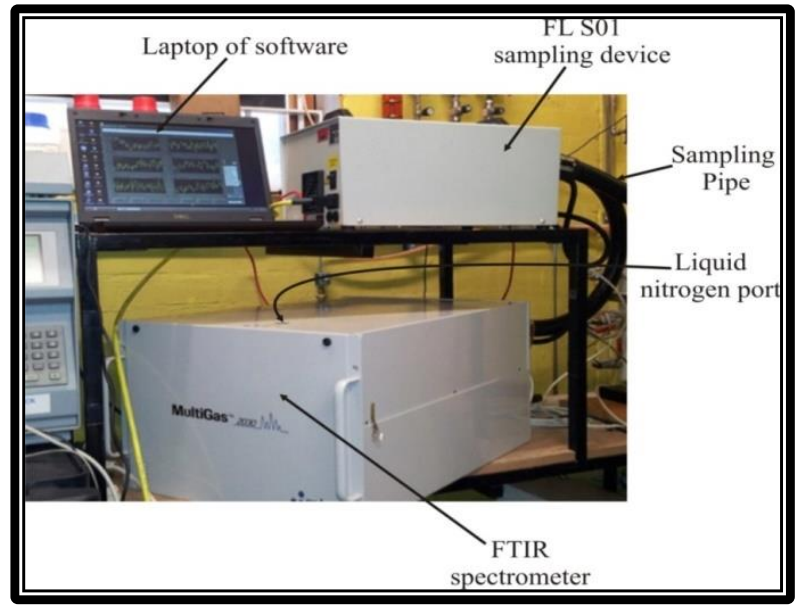

Fig. 5 The picture of Multigas 2030 FTIR

Table 3 typical diesel emission components measured by FTIR

\begin{tabular}{|c|c|c|c|}
\hline $\mathrm{NO}$ & Formaldehyde & $\mathrm{CO}$ & Acetylene \\
\hline $\mathrm{NO}_{2}$ & Acetaldehyde & Propylene & THC \\
\hline $\mathrm{N}_{2} \mathrm{O}$ & Acetone & Ethylene & NOx \\
\hline $\mathrm{NH}_{3}$ & Urea & Methane & Diesel \\
\hline $\mathrm{HNCO}$ & $\mathrm{CO}_{2}$ & Ethane & $\mathrm{SO}_{2}$ \\
\hline
\end{tabular}

\section{Combustion analysis}

LabView was used to load the raw data into the Matlap program and the data was processed using the traditional first low of thermodynamic. The release model is as follows: Pressure inside the cylinder was treated to extract peak pressure, the angle of peak pressure, the start of combustion and peak pressure angle, apparent heat release rate (AHRR) [58], without any heat transfer models or incision effects. The total heat release rate reflects the losses resulting from heat transfer to the cylinder walls and exits with exhaust gases. In this study, equation (1) was used to calculate the heat release rate depending on the energy balance in the combustion chamber and the first law of thermodynamics.

$\delta Q_{c h}=d U_{s}+\delta Q_{h t}+\delta W+\sum h_{i} d m_{i}$

Equation (1) can be modified to:

$\frac{d Q_{c h}}{d \theta}=\frac{\gamma}{\gamma-1} p \frac{d V}{d \theta}+\frac{1}{\gamma-1} V \frac{d p}{d \theta}+V_{c r} \frac{d p}{d \theta}+\frac{d Q_{h t}}{d \theta}$

The formula can be redrafted without correcting the loss of heat through the walls of the cylinder:

$\frac{d Q_{c h a}}{d \theta}=\frac{\gamma}{\gamma-1} p \frac{d V}{d \theta}+\frac{1}{\gamma-1} V \frac{d p}{d \theta}$

Net heat release calculations (apparent) are applied to the first two relationships and reflect a reasonable change in energy and work transition to the piston (Equivalent 2).

References $[59,60]$ mentioned that a certain temperature has a strong effect on the peak heat release rate within the combustion chamber. The heat constant typically ranges between 1.3 and 1.35 [58]. Since this study focuses on the use of different fuels and different engine operating conditions, a heat constant of 1.35 was used. The apparent heat release rate (AHRR) was calculated as the sum of the net heat release rates in each CAD starting from the beginning of the injection and can be expressed as follows:

$A H R R=\sum_{S O I}^{C A D}=720 \frac{d Q_{c h}(i)}{d \theta(i)} \cdot k(i)$ 
The definitions used in the study that represented the parameters of AHRR are described in Fig. 6. Each data set consists of 100 compression cycles used to generate one medium pressure. This procedure has been used to reduce noise while maintaining basic combustion characteristics. All heat release variables were calculated from the AHRR curve without filtering or using an average calculation, except for the combustion end zone, as the arithmetic mean was used to improve consistency.

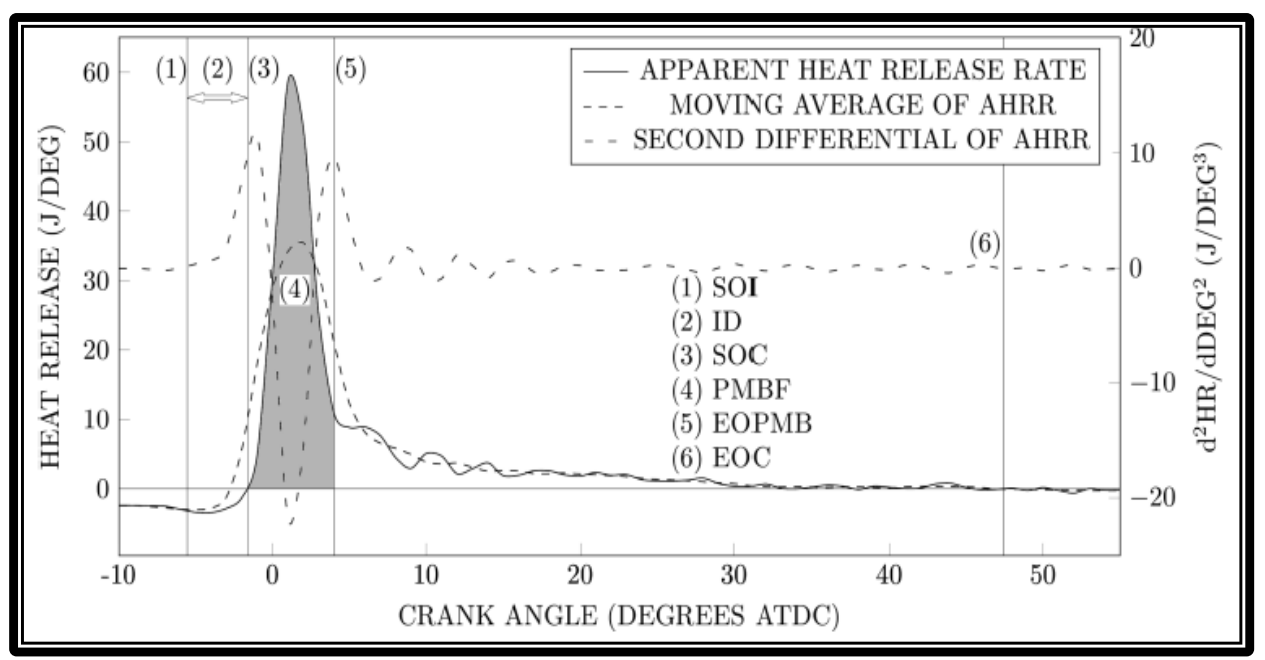

Fig. 6 a graph explaining the heat release and the definitions derived from it, to calculate the combustion criteria

BSFC is defined by the following formula:

$$
B S F C=\frac{m_{f}^{\circ}}{P}
$$

\section{Test conditions}

Single injection strategy was used in the experiments to evaluate the ULSD and EM combustion, and to measure practically the regulated and unregulated exhaust emissions characteristics. The in-cylinder pressure was measured using a pressure transducer; (LABVIWE) program was used to analyze the resulted signals. By this program we were able to evaluate: Apparent heat release rate, start of combustion, ignition delay, combustion duration and brake specific fuel consumption. Also, this program enabled to specify the amount of heat released during the premixed and diffusion combustion phases (premixed burn fraction PMBF) and (diffusion burn fraction DBF). NOx, CO, THC and smoke number (SN) were measured as described above. The unregulated pollutants measured were: Aldehydes (Formaldehyde and Acetaldehyde), Acetone, Ammonia, and Isocyanic acid.

\section{Results and Discussions}

\section{Combustion characteristics}

Fuel properties are changed when using a water-diesel emulsion compared to ULSD. In this study, the engine was always run by two specified loads 2.5 and 5 bars while the engine speed was remained at (1500 rpm). Single injection strategy (injection timing was varied by $-12,-9,-6,-3$, and $0^{\circ}$ ATDC), and constant fuel injection pressure (800 bars) were used in the tests.

Fig. 7 A, B, C, and D show the effect of injection timings and engine load on in-cylinder pressure variations with crank angles for the tested fuels (ULSD \& EM). The maximum pressure value was decreased with the retardation of the injection timing to $0^{\circ} \mathrm{ATDC}$; also the combustion pressure peaks were shifted. In all tested injection timings cases, the late fuel's injection at TDC or during compression stroke leads to a reduction in the peak pressure due to fuel combustion during the expansion stroke. Fig. $7 \mathrm{C}$ shows that the pressure curve for injection timing $\left(-3^{\circ}\right.$ ATDC) continued to fall after TDC and then began to rise as a result of late combustion.

Figure 8 declares a comparison of pressure inside the cylinder at a crank angle when the engine was operated at an injection timing of ( $-9^{\circ}$ ATDC) and for both high and low loads. The EM pressure curves rise early for all tested loads, and the increase is slightly higher than ULSD when the engine is powered by high load due to the higher combustion chamber temperature. Cylinder pressure peaks appear at different times of injection in Fig. 8 due to the onset of combustion.

The AHRR was obtained using in-cylinder pressure data treated by MATLAB program. Fig. 9 A, B, C, and D represent the impact of injection timings on AHRR at tested loads for the examined fuels. The AHRR curves 
confirmed Fig. 7 outcomes as it indicates the same trend, as well as it support the Injection Delay period (ID) data presented in Fig. 11.

At low load, the injection timing retardation caused a released heat rate reduction, and a shifting of the combustion phase towards the expansion stroke. However, at high load, the heat released rate decreases for -12, $9,-6^{\circ}$ ATDC then returns to increase for injection timing ( $-3^{\circ}$ ATDC) and $\left(0^{\circ}\right.$ ATDC). This behavior can be referred to ignition delay increment at retarded injection timings which promotes fuel-air mixing, leading to a larger premixed burn fraction and hence higher peak AHRR at late injection conditions, as shown in Figures 11 and 12. All these are happening at a high temperature as a result of higher load combustion which leads to increase the heat released rate.

Fig. 10 shows the heat released plots of ULSD and EM ( $-9^{\circ}$ ATDC) at low and high loads. The advancement of combustion trend for EM, which we have observed in Fig. 7, can be clearly observed here. Also, the ID data presented in Fig. 11 indicates that the EM's ID always longer than ULSD's ID. EM longer ID was due to this fuel physicochemical property as the water content has high latent heat that absorbs significant part of the heat released in the power stroke.

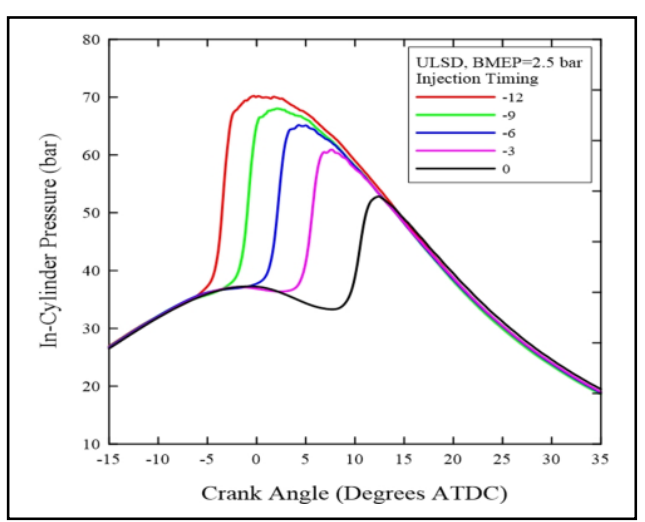

A

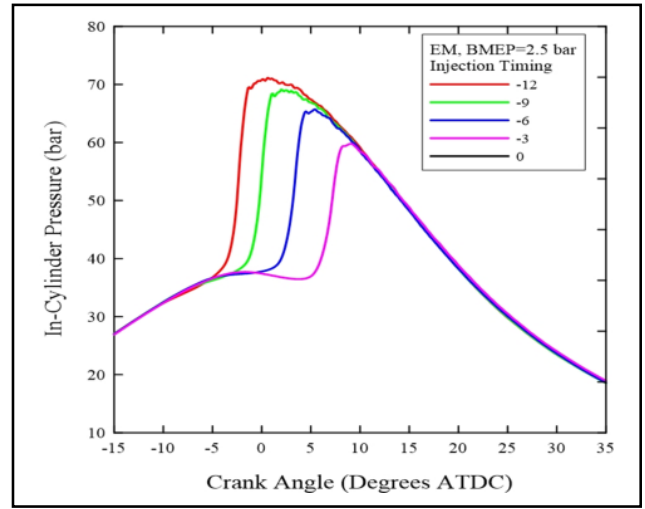

$\mathrm{C}$

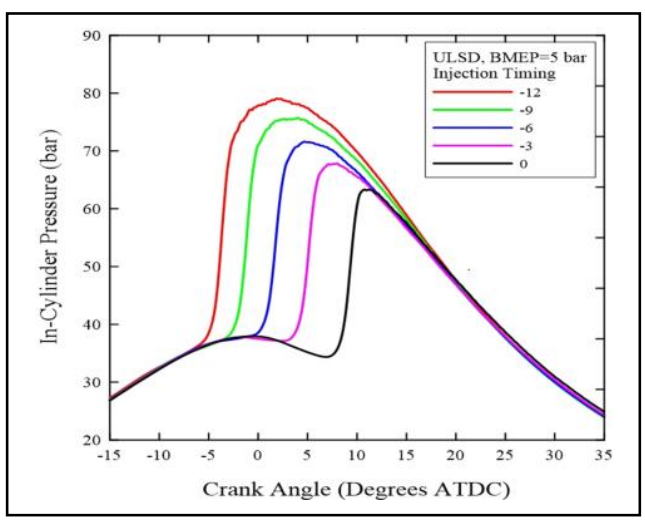

B

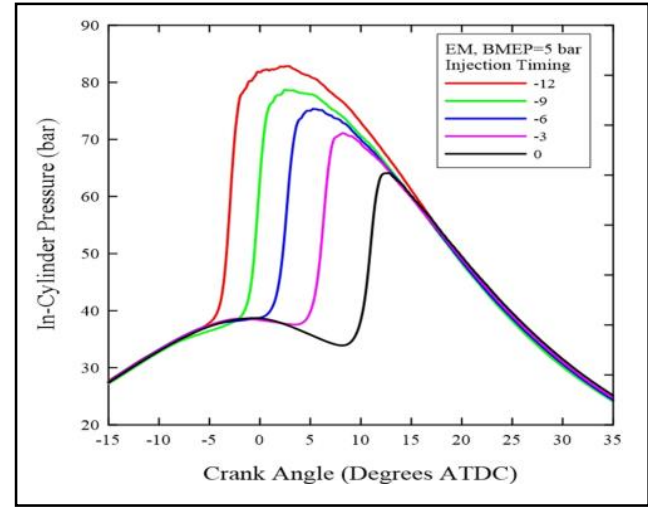

D

Fig. 7 In-cylinder pressure for the tested fuels at variable injection timing strategies

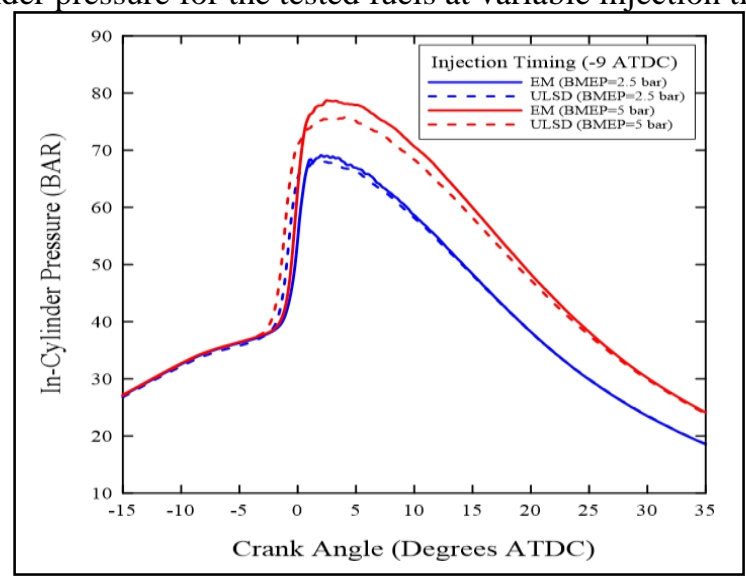

Fig. 8 In-cylinder pressure at injection timing (-9ATDC) under tested loads 
The fuel cetane number affects highly the ignition delay as if it is increased the self-ignition temperature decreased due to decrease of ignition delay. The EM has longer ignition delay (ID) compared to petrodiesel. This trend increased when operating at higher temperatures as in the case of higher engine load, because the water vaporization will happen more readily than at low temperatures, absorbing more combustion heat and increasing the physical component of ID time.

Fig. 12 depicts the difference between the heat released rate peaks at high and low load at different injection timings for ULSD and EM. The AHRR peak for EM at low and high load is higher than that for ULSD for all injection timings. This is due to enhancements in combustion resulted from micro- explosion that generated higher temperatures at all engine loads.

The EM longer ID increased the premixed burn fraction (PMBF) more than ULSD, as Fig. 13 shows. The EM's premixed burn fraction was increased by increasing load, while for the diffusion burn fraction it was reduced with load increase. The premixed diffusion burn of EM fuel increased for all tested injection timings and it was higher when the load was increased, as Fig. 14 reveals.

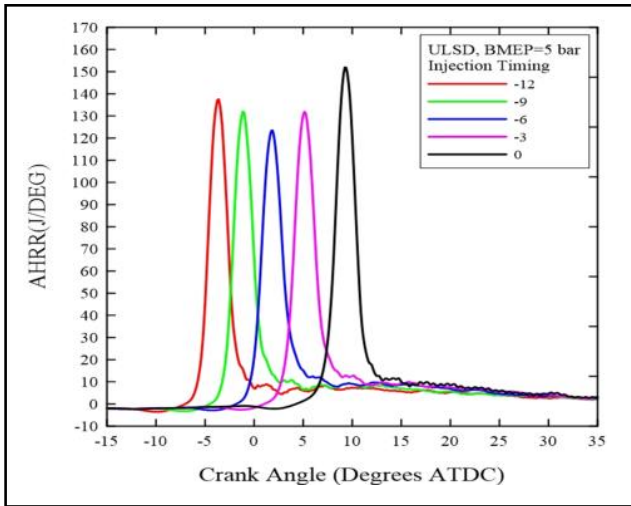

A

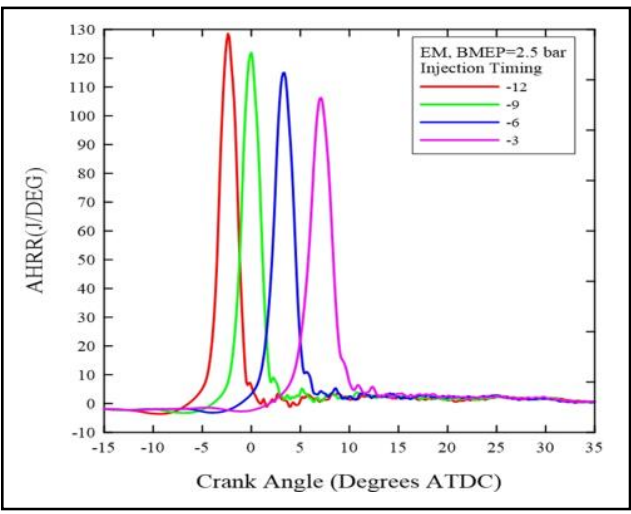

C

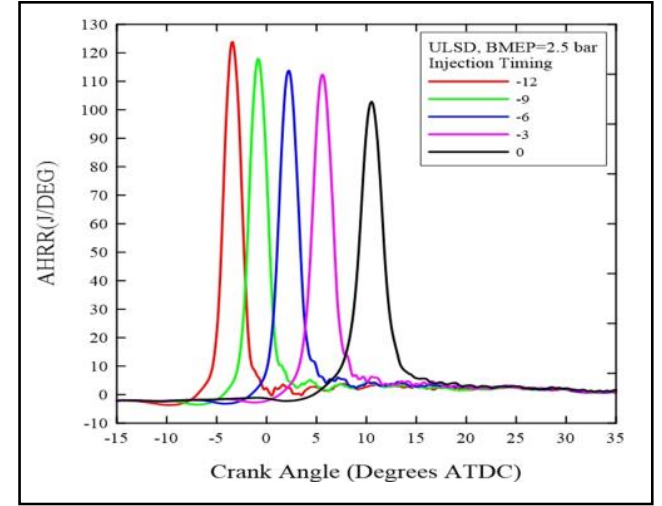

B

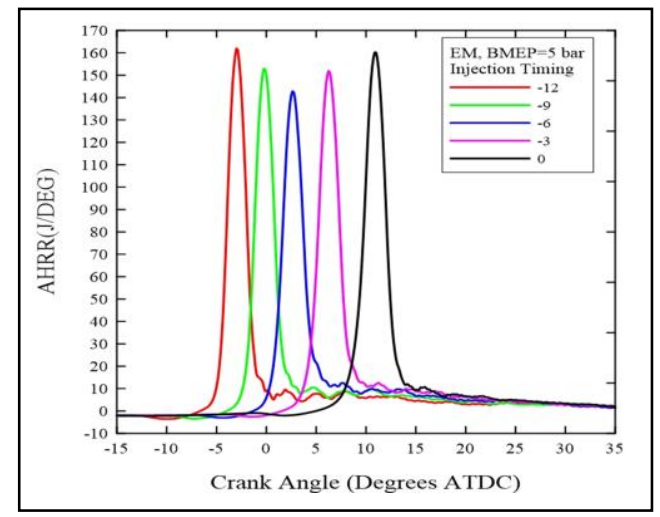

D

Fig. 9 Apparent heat release rate under low and high loads at variable injection timing strategies

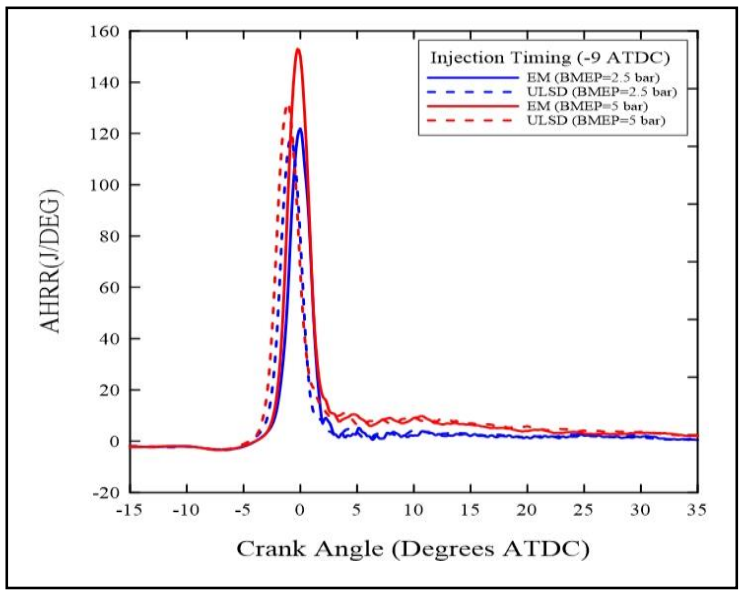


Fig. 10 apparent heat release rate strategies ( $-9^{\circ}$ ATDC) under low and high loads

The second differential of the heat released rate was used to calculate the premixed and diffusion combustion duration. In general, for both loads the diffusion combustion duration for EM was decreased when the injection timing was retarded while the opposite was occurred for premixed combustion duration. It was noticed that there is a significant difference in diffusion combustion duration at high and low load cases, however for the premixed combustion duration slight differences were noticed at both loads.
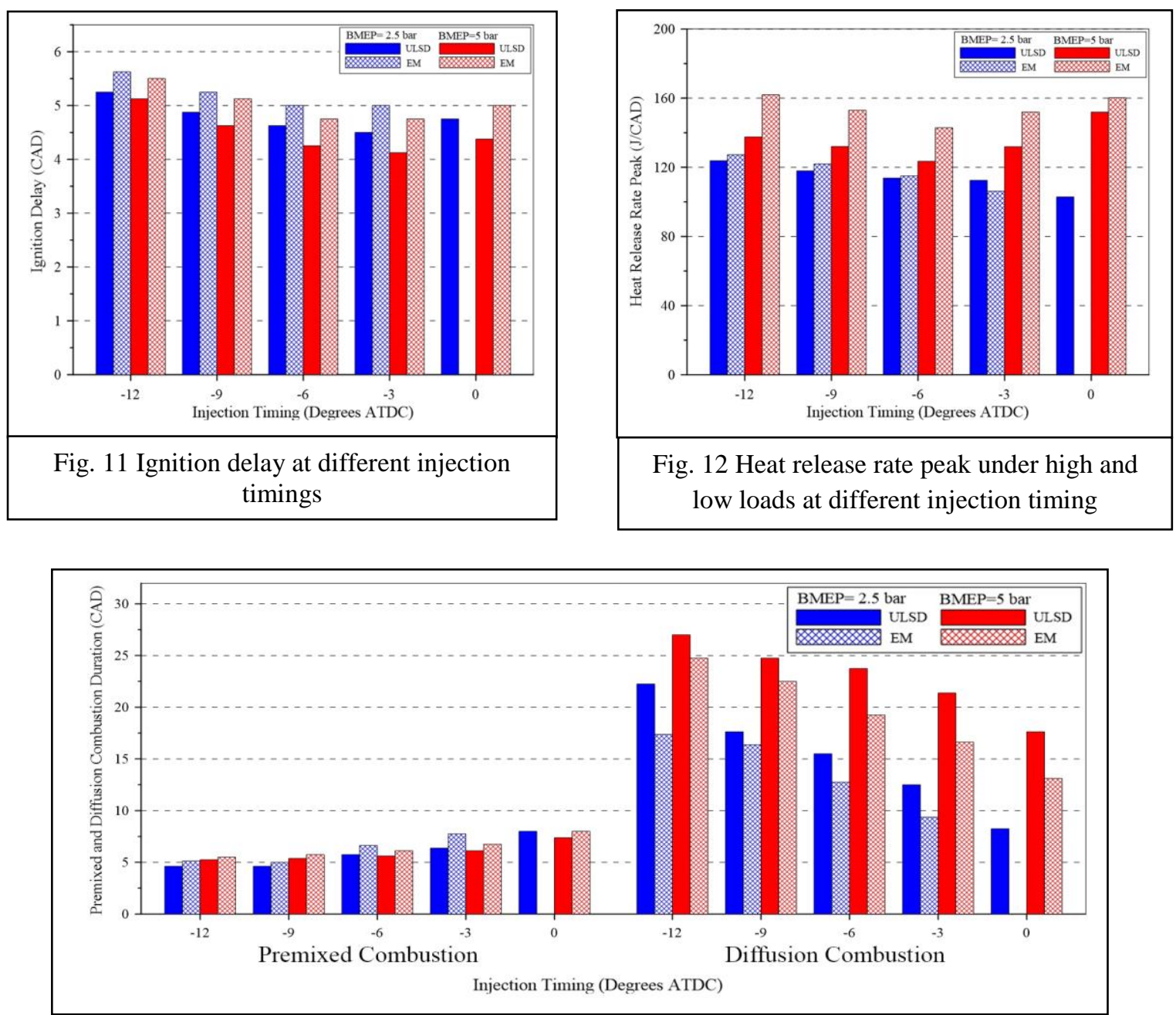

Fig. 13 premixed and diffusion combustion duration variation for the tested conditions

Fig. 14 shows the ULSD and EM fuels' BSFC at variable injection timings. The EM's BSFC was higher than ULSD at tested loads; this result is constituent with all the literature studied this material. The BSFC increase for EM compared to ULSD associated with the lower heat value of W/D emulsion compared to ULSD.

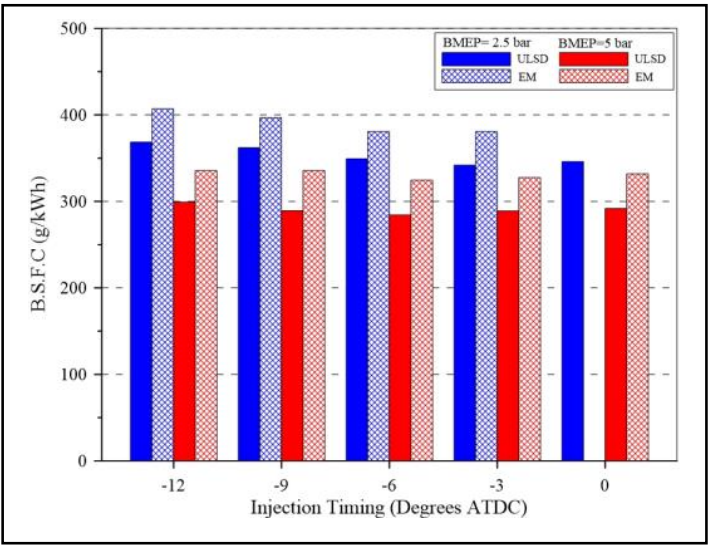


Fig. 14 Engine BSFC at variable injection timings and load for the tested fuels

2. Regulated emissions characteristics

Fig. 15 shows the impact of injection timings and load on $\mathrm{CO}$ emission. The variation in engine load has a direct effect on CO concentrations. CO levels when the engine was fueled with EM were high at low loads and reduced at high low compared to ULDF. The water existence in EM increase the ignition delay period and made some of the fuel to be burned at exhaust stroke that increased CO levels at low loads. At high loads, with higher heat release, the water existence enhanced the combustion due to micro-explosions and better oxidation for the carbon molecules with the increase of $\mathrm{OH}$ radicals from water dissociation. High $\mathrm{CO}$ concentrations were measured when injection timing was retarded.

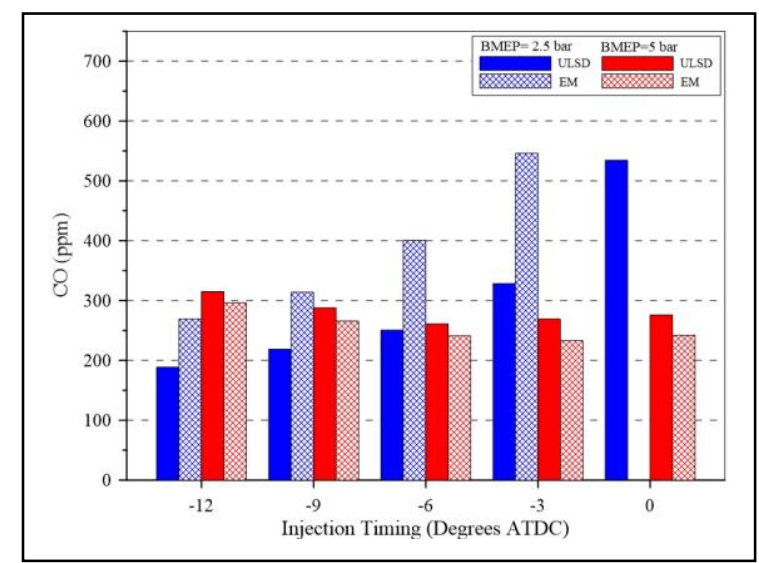

Fig. 15 CO levels for the tested fuels

Fig. 16 shows the characteristics of THC emissions. THC concentrations increased at low engine load relative to ULSD at $12^{\circ}$ ATDC, as the combustion chamber temperature is low when working at low load. These concentrations are clearly increased when the engine is powered by EM fuel. At high load, there is less sensitivity to use EM for all injection timings tested. HC are generally emitted as a result of failure to ignite a flame or a part of it, and are clearly associated with combustion period. It is noted from the figure that the engine did not work using the EM and injection timing of $0^{\circ}$ ATDC at low load due to combustion failure.

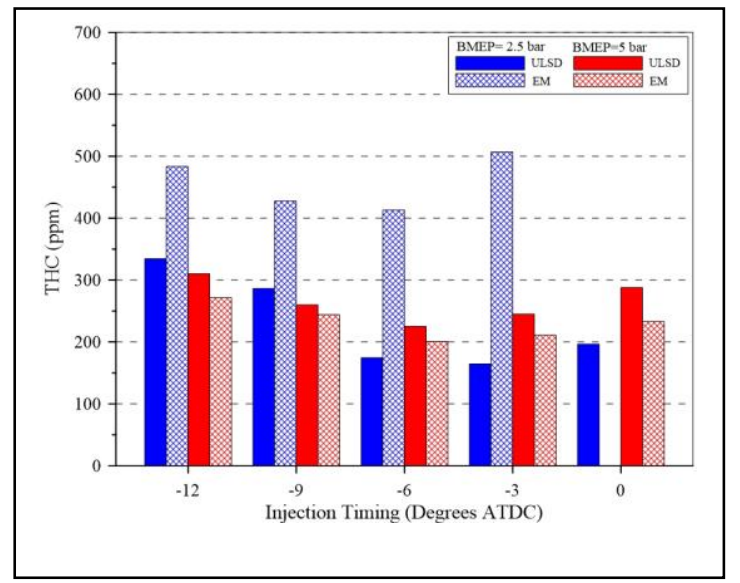

Fig. 16 Effect of load, injection timing, and fuel type on HC emitted

Figure 17 shows the change in nitrogen oxides emitted when the injection timing and load were changed. Retarding injection timing has greatly reduced NOx emissions as the formation of NOx components is frozen with the piston starts in the expansion stroke and lower cylinder temperature achieved. Also, the figure shows a significant difference in NOx emitted when the engine load was changed due to higher combustion temperature by increasing load. At all loads and injection timings tested, the NOx emissions with ULSD were higher than the NOx levels resulted from EM engine. All the researchers (who have studied this subject) have concluded that the presence of water causes a high reduction in combustion temperatures, which leads to decrease NOx concentrations. 


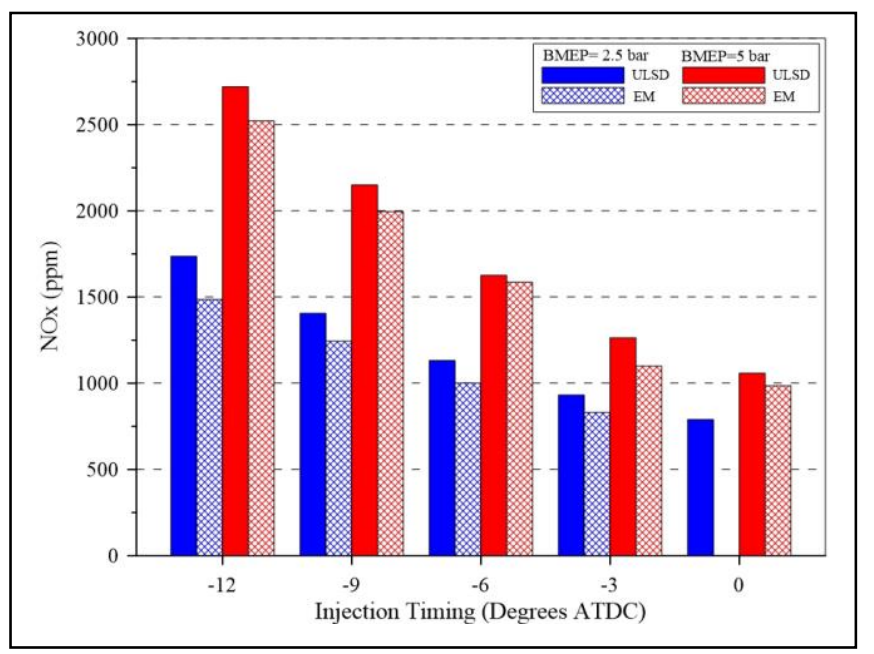

Fig. 17 Effect of load, fuel type, and injection timing on NOx emitted

The smoke number emitted by EM was lower than ULSD fuel, which is consistent with the results of published research in literature. The low smoke with EM can be attributed to increased $\mathrm{OH}$ radicals in fuel, as increasing oxygen content in the fuel can aid in reducing smoke formation during the diffusion combustion phase. The reduction of sulfur content in the base fluid (ULSD) has a great contribution in reducing smoke no. as well as water content.

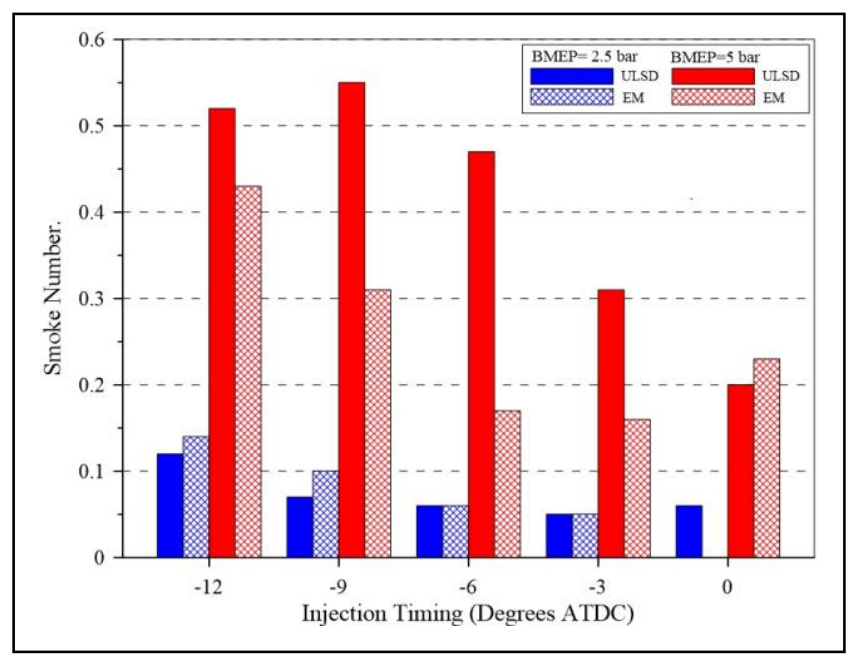

Fig. 18 Smoke Number variation for the tested fuels

C. Unregulated emissions characteristics

Formaldehyde is also called methanal $(\mathrm{CH} 2 \mathrm{O})$ is the simplest type of aldehydes [62]. This chemical compound is in the gaseous state at room temperature, it is colorless with an irritating and distinctive odor. Exposure to this gas causes poisoning and a danger to human health [63]. In 2011, formaldehyde was considered carcinogenic to humans according to the US National Toxicology Program [64].

Fig. 19 shows the changes in the formaldehyde levels emitted from the engine at $-9^{\circ}$ ATDC and injection pressure of 800 bars. The increase in engine load caused the formaldehyde concentrations of both fuels to be reduced, confirming that the temperature of in the combustion chamber has a significant role in formaldehyde formation [65]. The concentrations of this pollutant are sharply reduced by increasing the engine load and by increasing the temperature of the cylinder. Aldehydes are not present in diesel fuel but are formed during the combustion process and during the initial oxidative pyrolysis of fuel. Fig. 19 reveals that EM combustion produced more formaldehyde levels than ULSD. Low combustion temperatures due to water 
contained in the EM fuel can impede the degradation of esters and the removal of carboxylic, which causes increased formaldehyde.

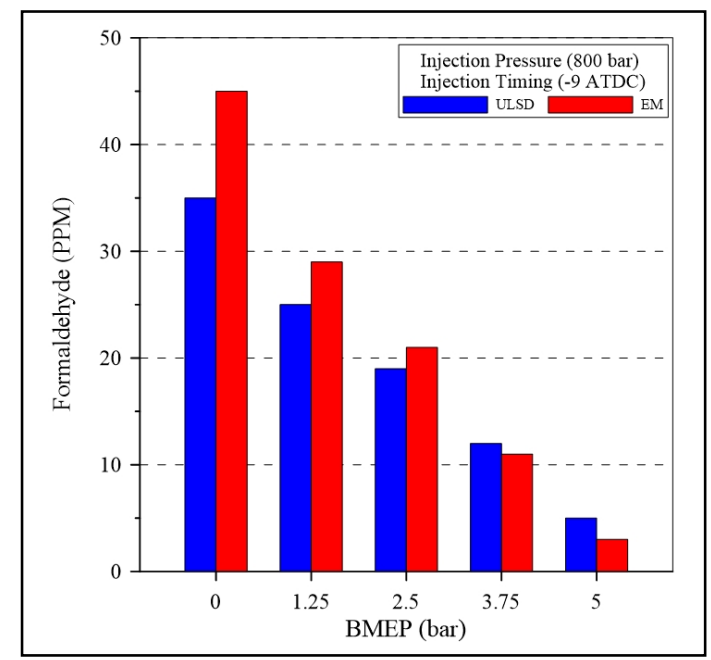

Fig. 19 Effect of load, fuel type, and injection timing on Formaldehyde levels

Acetaldehyde (also called ethanal) is an organic chemical compound with the formula $\mathrm{CH} 3 \mathrm{CHO}$. It is one of the most important aldehydes, which is generated in nature through industrial processes and is emitted from engine exhausts as well as the burning of tobacco [62]. The exposure to acetaldehyde for long periods causes poisoning, irritation as it also causes cancer [66, 67]. Fig. 20 indicates that the formation of acetaldehyde for both fuels decreased with the load increase. Acetaldehyde mainly originates from incomplete combustion of fuels. Low temperatures resulting from engine working at low loads help increase the formation of acetaldehyde. As the cylinder temperature increased, the engine load improved combustion and reduced acetaldehyde emissions. Working with EM fuel caused higher levels of acetaldehyde than ULSD for all engine loads except at 5 bars, because EM causes a greater reduction in combustion temperature and this is reflected in higher levels of acetaldehyde emitted.

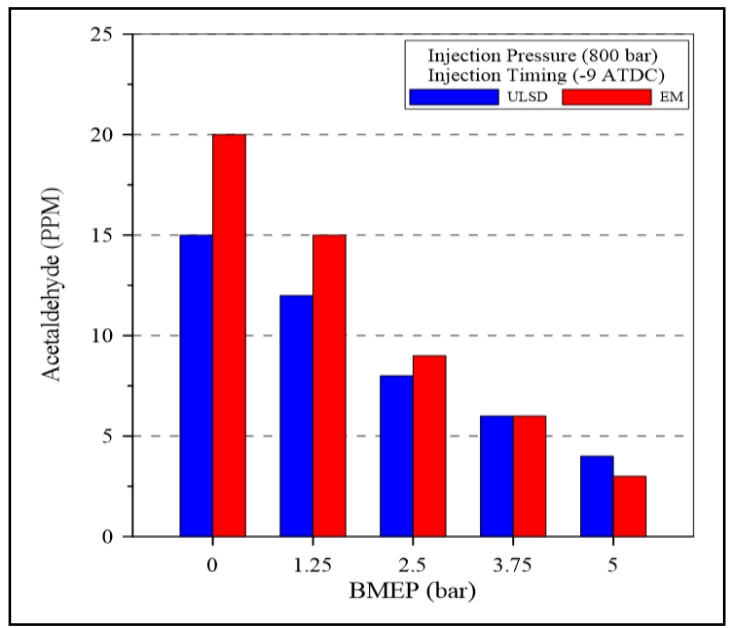

Fig. 20 Effect of fuel type and engine load on Acetaldehyde for the tested fuels

Fig. $21 \mathrm{~A}, \mathrm{~B}, \mathrm{C}$, and D depicts fuel type and engine load impact on the resulted hydrocarbon speciation. Hydrocarbon speciations are considered a volatile organic compound (VOC). Volatile organic compounds (VOCs) promote ozone production in surrounding conditions as well as being toxic and highly interactive in the atmosphere [68]. These compounds cause reduced visibility in the atmosphere as well as increased levels of ozone and organic PM [69].

Methane (Figure $21 \mathrm{~A}$ ) is a greenhouse gas with more than 20-fold efficiency in capturing solar radiation reflected from the Earth, causing global warming. This gas ages in the atmosphere for approximately from 9 to 15 years [70]. The figure indicates higher levels of methane at no and low load levels. EM generated higher levels of this pollutant at low loads and relatively lower concentrations at medium and high loads compared to ULSD. 
Acetylene is also called Ethyne $\left(\mathrm{C}_{2} \mathrm{H}_{2}\right)$, which is one of the simplest alkene; it is colorless, unsaturated gas because the two carbon atoms in its chemical composition are bound together in a triple bond [62].. Fig. 21 B reveals higher levels of this pollutant at no and low loads and it reduced at medium and high loads. In the same time, the burning of EM exhausted significantly higher level of Acetylene compared to diesel at no and low loads. At medium and high loads EM produced relatively lower levels than diesel. This result indicates the impact of combustion chamber temperature on Acetylene formation.

Ethylene (systematic name: ethene) is a hydrocarbon with the formula $\mathrm{C}_{2} \mathrm{H}_{4}$ or $\mathrm{H}_{2} \mathrm{C}=\mathrm{CH}_{2}$. It is a colorless flammable gas with a faint "sweet and musky" odor when pure. It is the simplest alkene and the simplest unsaturated hydrocarbon after acetylene $\left(\mathrm{C}_{2} \mathrm{H}_{2}\right)$ [71]. Ethylene's concentrations as Fig. $21 \mathrm{C}$ indicate the same trends of Acetylene, due to the same formations reasons.

Propylene is also called Propene or methylethylene $\left(\mathrm{C}_{3} \mathrm{H}_{6}\right)$; it is an unsaturated organic compound that has one double bond. Propylene is considered as the second simplest member of the alkene family. Propylene has low acute toxicity from inhalation [227]. The exhausted Propylene of EM (as Fig. 21 D shows) was high at no and low load and they are much higher than what ULSD emitted. At engine loads as 3.5 and 5 bars the Propylene concentrations of EM engine were lower than that of ULSD. The cause can be attributed to the degree of heat associated with combustion, which means that all these pollutants are increased by the low temperature of the combustion chamber associated with burning of EM fuel at low loads.

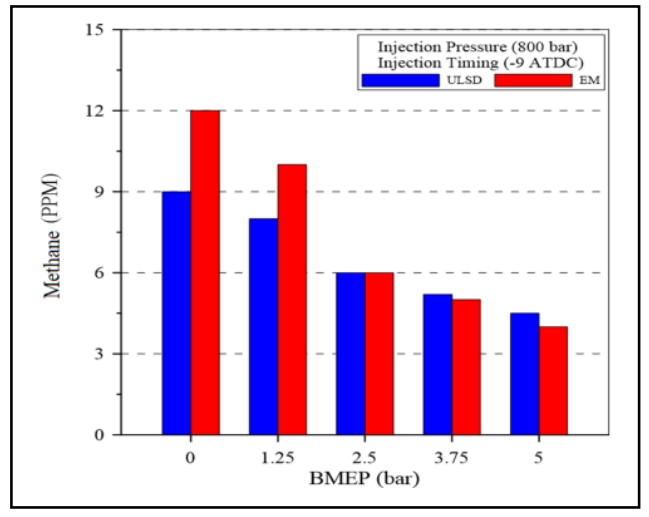

A

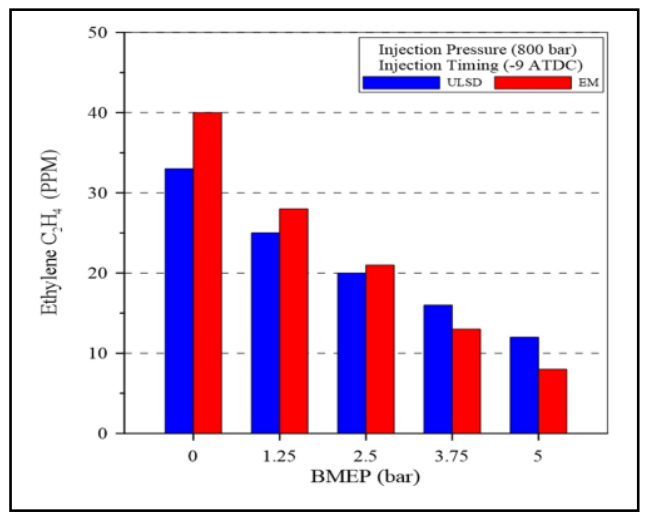

$\mathrm{C}$

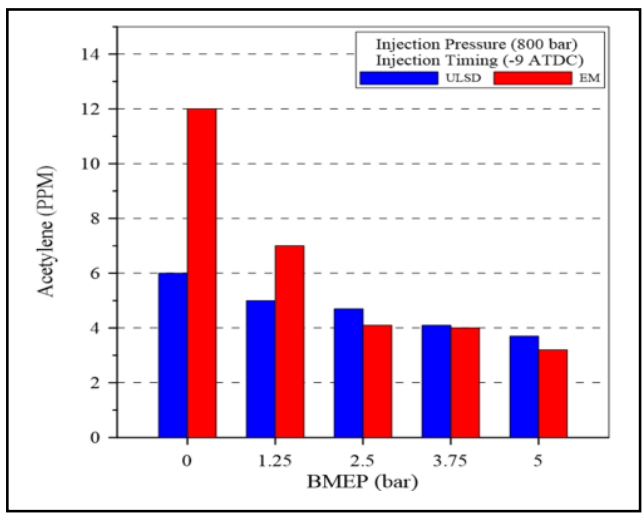

B

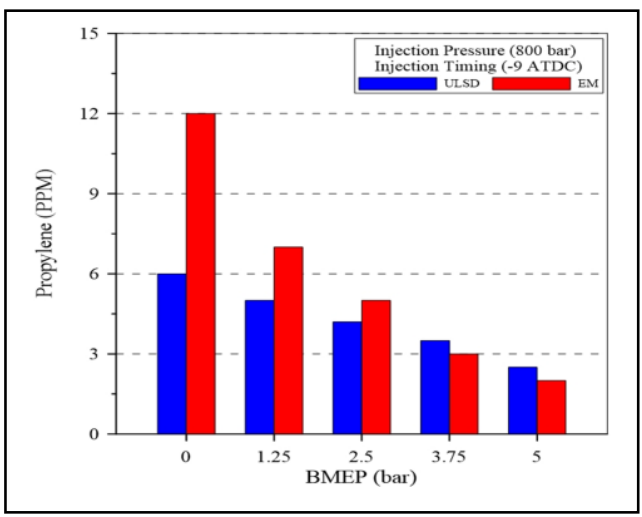

$\mathrm{D}$

Fig. 21 Effect of fuel type and engine load on Methane, Astylene, Ethylene, and propylene emissions for the tested fuels

Ammonia $\left(\mathrm{NH}_{3}\right)$ is a colorless gas with a characteristic pungent smell, and although it is wide used, ammonia is considered both caustic and hazardous [62]. Ammonia is an alkaline gas that contributes to the mass of fine PM that reduces vision. Ammonia vapor also causes severe irritation to the eyes and respiratory tract. Ammonia within the combustion chamber depends on temperature and availability of hydrogen [72]. The relatively high level of $\mathrm{NH} 3$ from the engines of vehicles using natural gas as fuel has increased interest in this pollutant [73]. Fig. 22 shows that the levels of ammonia are equal to zero at the low loads of both fuels and these levels started to increase by increasing the load. The maximum emission rate of ammonia recorded was less than $8 \mathrm{ppm}$ at 5 bars load while using EM emitted lower levels at the same load. This result indicates the importance of combustion heat in the formation of ammonia within the combustion chamber. 


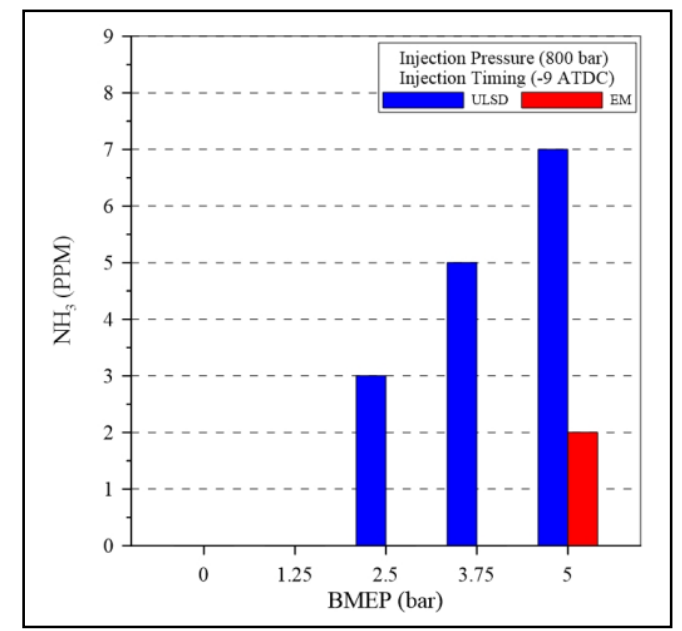

Fig. 22 Effect of fuel type and engine load on NH3 emissions for the tested fuels

Acetone named also propanone $\left.\left(\mathrm{CH}_{3}\right)_{2} \mathrm{CO}\right)$ is a colorless, flammable liquid, and it is considered as the simplest type of ketones that is thought to cause mild poisoning in normal use cases. Fig. 23 shows the engine load impact on emitted acetone levels. Acetone rates are relatively higher at low engine load and became lower at high loads, indicating the effect of heat within the combustion chamber on this pollutant formation. Compared with ULSD fuel, Acetone emissions of EM fuel were higher, the $\mathrm{OH}$ radicals existed in the EM combustion process may promotes the formation of acetone emissions.

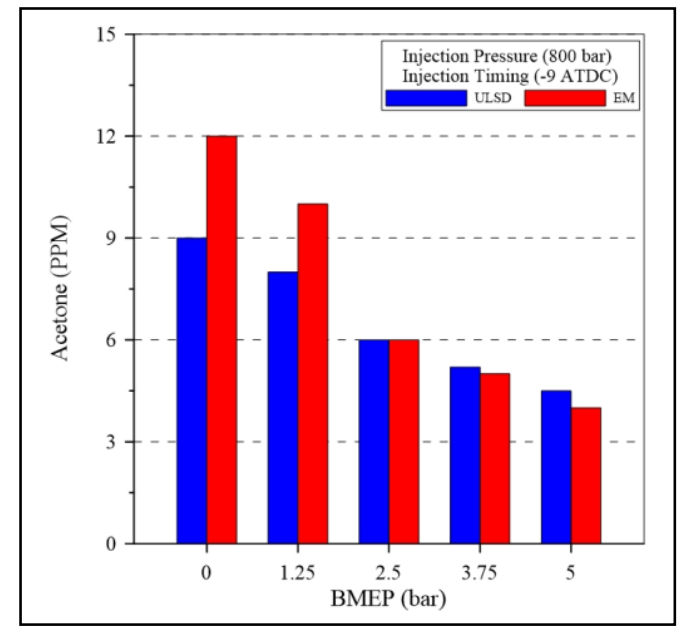

Fig. 23 Effect of fuel type and engine load on NH3 emissions for the tested fuels

\section{Conclusion}

The paper examined the characteristics of combustion; regulated and unregulated pollutants emitted from the combustion of ULSD and emulsified water-diesel containing surfactant to increase the stability of the mixture. The results of the study showed that the boiling process of the liquid phase mentioned by most researchers in this regard caused obvious reduction in AHRR. The low combustion temperatures associated with the burning of diesel-water emulsion caused the reduction of NOx and PM concentrations together, and caused a longer delay period compared to ULSD. When EM was used, the diffusion combustion duration decreased at retarding the injection timing while the opposite was occurred for premixed combustion duration. The BSFC of EM engine is higher than ULSD.

NOx and smoke No. were reduced together when using the water-diesel emulsion at all the injection timings tested. $\mathrm{CO}$ and $\mathrm{HC}$ were significantly increased at retarded injection timings and somewhat lower at advanced injection timings. Overall, the concentrations of these two contaminants were high. The unregulated emissions (Formaldehyde, Acetaldehyde, Methane, Acetylene, Ethylene, and propylene, Ammonia, and Acetone) were measured. The results were somewhat frustrating, as these hazardous pollutants to public health were all increased when using diesel-water emulsion. The low temperatures of the combustion chamber that causes less 
NOx levels is the same cause of increased unregulated pollutants. Therefore, it is necessary to find solutions capable of disrupting such serious missions, whether in the operating mode or by adding additives to prevent the formation of these emissions before advise of using emulsion fuels in diesel engines. The results of the study showed that the use of AM at medium and high engine's loads and speeds safe and cause a decrease in all exhaust pollutants in varying proportions, but its use during the engine's cold starting and warming-up period is risky.

Acknowledgements

The researchers highly thank the staff of the Centre for Advanced Research in Power Generation and Fuel (CAPF), Faculty of Engineering and Design, Brunel University, London, UK.We extend our thanks and appreciation to the technician Kenneth Antiss and to colleagues Fanos Christodoulou and David Peirce.

\section{References}

[1] Jamuwa DK, Sharma D, Soni SL. Experimental investigation of performance, exhaust emission and combustion parameters of stationary compression ignition engine using ethanol fumigation in dual fuel mode. Energy Convers Manage .31-115:221;2016.

[2] Syed Javed YVVSM, Satyanarayana MRS, Rajeswara Reddy R, Rajagopal K. Effect of a zinc oxide nanoparticle fuel additive on the emission reduction of a hydrogen dual-fuelled engine with jatropha methyl ester biodiesel blends. J Cleaner Prod .506-137:490;2016.

[3] Al-Maamary H M S, Kazem H A, Chaichan M T, The impact of the oil price fluctuations on common renewable energies in GCC countries, Renewable and Sustainable Energy Reviews, vol. 75, pp. 989-1007, 2017. [4] ] Mohd FO, Abdullah A, Najafi G, Rizalman M. Green fuel as alternative fuel for diesel engine: a review. Renew Sustain Energy Rev 2017; 80: 694-709.

[5] Eivaz Akbariana, Bahman Najafib, A novel fuel containing glycerol triacetate additive, biodiesel and diesel blends to improve dual-fuelled diesel engines performance and exhaust emissions, Fuel 236 (2019) 666-676

[6] Mohsin R, Majid ZA, Shihnan AH, Nasri NS, Sharer Z. Effect of biodiesel blends on engine performance and exhaust emission for diesel dual fuel engine. Energy Convers Manage 2014; 88: 821-8.

[7] Jiaqiang E, Zhiqing Zhang, Jingwei Chen, MinhHieu Pham, Xiaohuan Zhao, Qingguo Peng, Bin Zhang, Zibin Yin, Performance and emission evaluation of a marine diesel engine fueled by water biodiesel-diesel emulsion blends with a fuel additive of a cerium oxide nanoparticle, Energy Conversion and Management 169 (2018) 194-205

[8] Chaichan M T, Performance and emissions characteristics of CIE using hydrogen, biodiesel, and massive EGR, International Journal of Hydrogen Energy, vol. 43, pp. 5415-5435, 2018. https://doi.org/10.1016/j.ijhydene.2017.09.072

[9] Debnath BK, Saha UK, Sahoo N. A comprehensive review on the application of emulsions as an alternative fuel for diesel engines. Renew Sust Energ Rev 2015;42:196-211.

[10] Ahmad Muhsin Ithnin, Wira Jazair Yahya, Mohamad Azrin Ahmad, Nur Atiqah Ramlan, Hassanuddin Abdul Kadir, Nor Azwadi Che Sidik, Tsuyoshi Koga, Emulsifier-free Water-in-Diesel emulsion fuel: Its stability behaviour, engine performance and exhaust emission, Fuel 215 (2018) 454-462.

[11] Hasannuddin AK, Wira JY, Sarah S, Ahmad MI, Aizam SA, Aiman MAB, et al .Durability studies of single cylinder diesel engine running on emulsion fuel. Energy 2016; 557: 68-94.

http://dx.doi.org/10.1016/j.energy.2015.10.144.

[12] Reza Najjar, Somaiyeh Heidari, Modified diesel prepared by stabilization of water as nanodroplets in diesel/colza oil blend: Study of phase behavior and affecting parameters, Fuel 214 (2018) 497-504

[13] Yang WM, An H, Chou SK, Chua KJ, Mohan B, Sivasankaralingam V, et al. Impact of emulsion fuel with nano-organic additives on the performance of diesel engine. Appl Energy 2013. http://dx.doi.org/10.1016/j.apenergy.2013.02.027.

[14] Nadeem M, Rangkuti C, Anuar K, Haq MRU, Tan IB, Shah SS. Diesel engine performance and emission evaluation using emulsified fuels stabilized by conventional and gemini surfactants. Fuel 2006; 85: 2111-9. http://dx.doi.org/10.1016/j.fuel.2006.03.013.

[15] Schramm J, Sigvardsen RS, Forman M. Bitumen/water emulsions as fuels for high speed CI engines preliminary investigations. SAE Pap 2003;2003-01-31.

[16] Hagos FY, Aziz ARA, Tan IM. Water-in-diesel emulsion and its micro-explosion phenomenon-review. In: Commun. Softw. Networks (ICCSN), 2011 IEEE 3rd Int. Conf., IEEE; 2011, p. 314-8. doi:10.1109/ICCSN.2011.6014903.

[17] Hasannuddin AK, Wira JY, Srithar R, Sarah S, Ahmad MI, Aizam SA, et al. Effect of emulsion fuel on engine emissions - a review. Clean Technol Environ Policy 2015.

http://dx.doi.org/10.1007/s10098-015-0986-X. 
[18] Watanabe H, Suzuki Y, Harada T, Matsushita Y, Aoki H, Miura T. An experimental investigation of the breakup characteristics of secondary atomization of emulsified fuel droplet. Energy 2010; 35(2): 806-813.

[19] Hyemin Kim, Jonghan Won, Seung Wook Baek, Evaporation of a single emulsion fuel droplet in elevated temperature and pressure conditions, Fuel 226 (2018) 172-180

[20] Kim H, Baek SW. Combustion of a single emulsion fuel droplet in a rapid compression machine. Energy 2016; 106: 422-30.

[21] Kegl B, Pehan S. Reduction of diesel engine emissions by water injection. SAE Technical Paper. 2001; 2001-01-3259.

[22] Alahmer A, Yamin J, Sakhrieh A, Hamdan MA. Engine performance using emulsified diesel fuel. Energy Convers Manage 2010;51:1708-13.

[23] Tauzia X, Maiboom A, Shah SR. Experimental study of inlet manifold water injection on combustion and emissions of an automotive direct injection Diesel engine.

Energy 2010;35:3628-39.

[24] Fahd MEA, Yang WM, Lee PS, Chou SK, Yap CR. Experimental investigation of the performance and emission characteristics of direct injection diesel engine by water emulsion diesel under varying engine load condition. Appl Energy

2013;102:1042-9.

[25] Yang WM, An H, Chou SK, Chua KJ, Mohan B, Sivasankaralingam V, et al. Impact of emulsion fuel with nano-organic additives on the performance of diesel engine. Appl Energy 2013;112:1206-12.

[26] Ithnin AM, Ahmad MA, Bakar MAA, Rajoo S, Yahya WJ. Combustion performance and emission analysis of diesel engine fuelled with water-in-diesel emulsion fuel made from low-grade diesel fuel. Energy Convers Manage 2015;90:375-82.

[27] Liang Y, Shu G, Wei H, Zhang W. Effect of oxygen enriched combustion and water-diesel emulsion on the performance and emissions of turbocharged diesel engine. Energy Convers Manage 2013;73:69-77.

[28] Mura E, Calabria R, Califano V, Massoli P, Bellettre J. Emulsion droplet microexplosion: analysis of two experimental approaches. Exp Therm Fluid Sci 2014;56:69-74

[29] Morsy MH. Assessment of a direct injection diesel engine fumigated with ethanol/water mixtures. Energy Convers Manage 2015; 94: 406-14.

[30] Huo M, Lin S, Liu H, Lee C-fF. Study on the spray and combustion characteristics of water-emulsified diesel. Fuel 2014; 123: 218-29.

[31] Ithnin AM, Noge H, Kadir HA, Jazair W. An overview of utilizing water-in-diesel emulsion fuel in diesel engine and its potential research study. J Energy Inst 2014; 87: 273-88.

[32] Vellaiyan S, Amirthagadeswaran KS. The role of water-in-diesel emulsion and its additives on diesel engine performance and emission levels: a retrospective review. Alexandria Eng J 2016; 5: 2463-72.

[33] Li T, Zhang X-Q, Wang B, Guo T, Shi Q, Zheng M. Characteristics of non-evaporating, evaporating and burning sprays of hydrous ethanol diesel emulsified fuels. Fuel 2017; 191: 251-65.

[34] Wang ZW, Chen X, Huang S, Chen YL, Mack JH, Tang J, et al. Visualization study for the effects of oxygen concentration on combustion characteristics of wateremulsified diesel. Fuel 2016; 177: 226-34.

[35] Subramanian KA. A comparison of water-diesel emulsion and timed injection of water into the intake manifold of a diesel engine for simultaneous control of NO and smoke emissions. Energy Convers Manage 2011; 52: 849-57.

[36] Yang WM, An H, Chou SK, Chua KJ, Mohan B, Sivasankaralingam V, et al. Impact of emulsion fuel with nano-organic additives on the performance of diesel engine. Appl Energy 2013; 112: 1206-12.

[37] Ma Y, Huang S, Huang R, Zhang Y, Xu S. Spray and evaporation characteristics of npentanoldiesel blends in a constant volume chamber. Energy Convers Manage 2016;130:240-51

[38] Iwai M, Yoshida K, Iijima A, Shoji H. Study on Performance of diesel engine applied with emulsified diesel fuel: the influence of fuel injection timing and water contents. SAE Technical Paper. 2011; 2011-32-0606.

[39] R. Vigneswarana, K. Annamalaib, B. Dhineshc, R. Krishnamoorthy, Experimental investigation of unmodified diesel engine performance, combustion and emission with multipurpose additive along with water-in diesel emulsion fuel, Energy Conversion and Management 172 (2018) 370-380

[40] Zhaowen Wang, Shuguo Shi, Sheng Huang, Jie Tang, Tao Du, Xiaobei Cheng, Ronghua Huang, Jyh-Yuan Chen, Effects of water content on evaporation and combustion characteristics of water emulsified diesel spray, Applied Energy 226 (2018) 397-407

[41] Elsanusi OA, Roy MM, Sidhu MS. Experimental investigation on a diesel engine fueled by diesel-biodiesel blends and their emulsions at various engine operating conditions. Appl Energy 2017;203:582-93.

[42] Alahmer A. Influence of using emulsified diesel fuel on the performance and pollutants emitted from diesel engine. Energy Convers Manage 2013;73:361-9.

[43] Fahd MEA, Wenming Y, Lee PS, Chou SK, Yap CR. Experimental investigation of the performance and emission characteristics of direct injection diesel engine by water emulsion diesel under varying engine load condition. Appl Energy 2013;102:1042-9. 
[44] Ithnin AM, Noge H, Kadir HA, Jazair W. An overview of utilizing water-in diesel emulsion fuel in diesel engine and its potential research study. J Energy Inst 2014; 87(4): 273e88.

[45] Koc AB, Abdullah M. Performance and NOx, emissions of a diesel engine fueled with biodiesel-dieselwater nanoemulsions. Fuel Process Technol 2013; 109: 70-7.

[46] A.K. Hasannuddin, W.J. Yahya, S. Sarah, A.M. Ithnin, S. Syahrullail, N.A.C. Sidik, K.A. Abu Kassim, Y. Ahmad, N. Hirofumi, M.A. Ahmad, D.A. Sugeng, M.A. Zuber, N.A. Ramlan, Nano-additives incorporated water in diesel emulsion fuel: Fuel properties, performance and emission characteristics assessment, Energy Conversion and Management 169 (2018) 291-314

[47] Jiaqiang E, Zhiqing Zhang, Jingwei Chen, MinhHieu Pham, Xiaohuan Zhao, Qingguo Peng, Bin Zhang, Zibin Yin, Performance and emission evaluation of a marine diesel engine fueled by water biodiesel-diesel emulsion blends with a fuel additive of a cerium oxide nanoparticle, Energy Conversion and Management 169 (2018) 194-205

[48] Miqdam Tariq Chaichan, Abdul Amir H. Kadhum, Ahmed A. Al-Amiery, Novel technique for enhancement of diesel fuel: Impact of aqueous alumina nano-fluid on engine's performance and emissions, Case Studies in Thermal Engineering 10 (2017) 611-620

[49] Avinash Kumar Agarwal, Pravesh Chandra Shukla, Chetankumar Patel, Jai Gopal Gupta, Nikhil Sharma, Rajesh Kumar Prasad, Rashmi A. Agarwal, Unregulated emissions and health risk potential from biodiesel (KB5, KB20) and methanol blend (M5) fuelled transportation diesel engines, Renewable Energy 98 (2016) $283 \mathrm{e} 291$.

[50] Yage Di, C.S. Cheung, Zuohua Huang, Experimental investigation on regulated and unregulated emissions of a diesel engine fueled with ultra-low sulfur diesel fuel blended with biodiesel from waste cooking oil, Science of the total environment 407 (2009) 835-846

[51] Meisam Ahmadi Ghadikolaei, Effect ofalcoholblendandfumigationonregulatedandunregulated emissions ofICengines - A review, Renewable and Sustainable Energy Reviews 57(2016)1440-1495.

http://dx.doi.org/10.1016/j.rser.2015.12.128

[52] Imad A. Khalek, Matthew G. Blanks, Patrick M. Merritt, and Barbara Zielinska, Regulated and unregulated emissions from modern 2010 emissions-compliant heavy-duty on-highway diesel engines, Journal of the Air \& Waste Management Association, 65(8):987-1001, 2015.

[53] X.J. Man, C.S. Cheung, Z. Ning, L. Wei, Z.H. Huang, Influence of engine load and speed on regulated and unregulated emissions of a diesel engine fueled with diesel fuel blended with waste cooking oil biodiesel, Fuel 180 (2016) 41-49.

[54] S.G. Poulopoulos, D.P. Samaras, C.J. Philippopoulos, Regulated and unregulated emissions from an internal combustion engine operating on ethanol-containing fuels, Atmospheric Environment 35 (2001) 4399-4406.

[55] Paramvir Singh,Varun, S.R. Chauhan, Carbonyl and aromatic hydrocarbon emissions from diesel engine exhaust using different feedstock: A review, Renewable and Sustainable Energy Reviews 63 (2016) 269-291.

http://dx.doi.org/10.1016/j.rser.2016.05.069

[56] Zervas E. Regulated and non-regulated pollutants emitted from two aliphatic and a commercial diesel fuel. Fuel 2008; 87: 1141-7.

[57] Zhang ZH, Cheung CS, Chan TL, Yao CD. Experimental investigation of regulated and unregulated emissions from a diesel engine fueled with Euro V diesel fuel and fumigation methanol. Atmos Environ 2010; 44: 1054-61.

[58] Heywood, J.B., 1988. Internal Combustion Engine Fundamentals. McGraw-Hill Science Engineering.

[59] U. Horn, R. Egnell, B. Johansson, O. Andersson. Detailed Heat Release Analyses With Regard To Combustion of RME and Oxygenated Fuels in an HSDI Diesel Engine. SAE, 2007-01-0627 (2007).

[60] R. Lanzafame, M. Messina. ICE gross heat release strongly influenced by specific heat ratio values. International Journal of Automotive Technology, 4 (2003), 125-133.

[61] Labecki, L., 2010. Combustion and emission characteristics of biofuels in diesel engines. PhD Theses,

Brunel University; School of Engineering and Design, UK.

[62] http://en.wikipedia.org

[63] Marina C. Rodrigues , Lílian L.N. Guarieiro , Manuela P. Cardoso , Luiz Souza Carvalho , Gisele O. da Rocha and Jailson B. de Andrade. Acetaldehyde and formaldehyde concentrations from sites impacted by heavy-duty diesel vehicles and their correlation with the fuel composition: Diesel and diesel/biodiesel blends. Fuel 92 (2012) 258-263.

[64] National Toxicology Program (10 June 2011). "Report On Carcinogens - Twelfth Edition - 2011" (PDF). National Toxicology Program. Retrieved 2011-06-11.

[65] Ruijun Zhu, C.S. Cheung, Zuohua Huang and Xibin Wang. Regulated and unregulated emissions from a diesel engine fueled with diesel fuel blended with diethyl adipate. Atmospheric Environment 45 (2011) 21742181.

[66] US Environmental Protection Agency. Chemical Summary for Acetaldehyde. 2013. 
[67] Yage D, Cheungb CS, Huang Z. Experimental investigation on regulated and unregulated emissions of a diesel engine fueled with ultra-low sulphur diesel fuel blended with biodiesel from waste cooking oil. Science of the Total Environment 2009; 407: 835-846.

[68] Jiun-Horng Tsai, Sheng-You Chang, Hung-Lung Chiang. Volatile organic compounds from the exhaust of light-duty diesel vehicles. Atmospheric Environment 61 (2012) 499-506.

[69] Carlton, A.G., Wiedinmyer, C., Kroll, J.H., 2009. A review of secondary organic aerosol (SOA) formation from isoprene. Atmospheric Chemistry and Physics 9, 4987-5005.

[70] Vicente Bermúdez, José M. Lujan, Benjamín Pla, Waldemar G. Linares. Effects of low pressure exhaust gas recirculation on regulated and unregulated gaseous emissions during NEDC in a light-duty diesel engine. Energy 36 (2011) 5655-5665.

[71] Lei Zhu, C.S. Cheung, W.G. Zhang, J.H. Fang , Zhen Huang. Effects of ethanol-biodiesel blends and diesel oxidation catalyst (DOC) on particulate and unregulated emissions. Fuel 113 (2013) 690-696(25 ch5))

[72] Fanos Christodoulou, Athanasios Megaritis. Experimental investigation of the effects of simultaneous hydrogen and nitrogen addition on the emissions and combustion of a diesel engine. International journal of hydrogen energy 39 (2014)2692-2702.

[73] Georgios Karavalakis , Maryam Hajbabaei, Thomas D. Durbin, Kent C. Johnson, Zhongqing Zheng, Wayne J. Miller. The effect of natural gas composition on the regulated emissions, gaseous toxic pollutants, and ultrafine particle number emissions from a refuse hauler vehicle. Energy 50 (2013) 280-291. 